\title{
A patient notification exercise following infection control failures in a dental surgery
}

\author{
B. W. Mason, ${ }^{1}$ J. Cartwright, ${ }^{2}$ S. Sandham, ${ }^{3}$ C. Whiteside ${ }^{4}$ \\ and R. L. Salmon ${ }^{5}$
}

- Demonstrates that the hepatitis $C$ virus was not transmitted from a dental healthcare worker to patients despite suboptimal infection control practice.

- Provides evidence which contributes to the debate on the need to restrict the practice of health professionals infected with blood-borne viruses.

- Suggests that patient notification or 'look back' exercises may be unnecessary in similar situations.

\begin{abstract}
Objectives To investigate the association between treatment by a dental healthcare worker (HCW) and patient infection with a blood-borne virus (BBV). Design Nested case control study. Setting A patient notification exercise (PNE) arising from a hepatitis $C$ virus positive HCW that was undertaken because of deficiencies in infection control practice. Methods Cases were individuals with a BBV infection identified as a result of the PNE. Controls were randomly selected individuals with negative tests for BBVs. Detailed information on dental treatment was obtained from patient notes. Information on risk factors for BBV infection was obtained using a structured questionnaire administered by telephone interview. Results Thirty patients had evidence of infection with a BBV. The mean number of visits for treatment was 20.5 in cases and 18.6 in controls; the difference $1.8(95 \% \mathrm{Cl}-5.4$ to 9.1$)$ was not statistically significant ( $p=0.62)$. Transmission of hepatitis $\mathrm{C}$ in the dental setting was excluded by sequencing of the viral genome or establishing alternative risk factors. Conclusion There was no evidence of transmission of hepatitis $C$ virus from the HCW to patients, or transmission of a BBV from patient to patient. To ensure consistent practice within the UK the National Institute for Health and Clinical Excellence should produce guidance on PNEs for the NHS.
\end{abstract}

\section{INTRODUCTION}

If transmission of hepatitis C virus (HCV) from an infected healthcare worker (HCW) to a patient is detected, notification of other patients of that HCW who have undergone exposure-prone procedures is usual practice. ${ }^{1}$ The Advisory Group on Hepatitis recommend that patient notification exercises (PNEs) should be carried out only when HCWto-patient transmission of HCV has been identified, and where a PNE is carried out, only patients who have undergone

\footnotetext{
${ }^{1 * 5}$ Consultant Epidemiologists, Communicable Disease Surveillance Centre Wales, National Public Health Service for Wales, The Temple of Peace and Health, Cathays Park, Cardiff, CF10 3NW; ${ }^{2}$ Specialist Registrar in Public Health, ${ }^{4}$ Consultant in Communicable Disease Control, Health Protection Team, National Public Health Service for Wales, Preswylfa, Hendy Road, Mold, CH7 $1 \mathrm{PZ} ;{ }^{3}$ Director of Dental Public Health, National Public Health Service for Wales, Royal Alexandra Hospital, Dental Department, Marine Drive, Rhyll, LL18 3AS

${ }^{*}$ Correspondence to: Dr Brendan W. Mason Email: brendan.mason@nphs.wales.nhs.uk
}

\section{Online article number E8}

Refereed Paper - accepted 23 April 2008

DOI: $10.1038 /$ sj.bdj.2008.656

${ }^{\circ}$ British Dental Journal 2008; 205: E8 a high-risk exposure-prone procedure (EPP) should be notified in the first instance. $^{2}$ A PNE is not usually undertaken when a HCV RNA positive HCW is identified in the absence of evidence of transmission. There is no guidance in the UK on managing patients exposed to instruments that are possibly contaminated with blood-borne viruses (BBVs). ${ }^{3}$

\section{BACKGROUND}

In October 2005, the National Public Health Service for Wales (NPHS) was formally notified of a case of RNA positive HCV infection in a HCW who was currently practising in a dental surgery. An incident management team was established to determine and implement all necessary action. Mapping of known HCV cases across the local health board (LHB) area did not demonstrate an excess in the locality surrounding the HCW's practice, and the distribution of the specific genotype was similar to that reported for Wales as a whole. A review of files held by the LHB relating to the practice revealed that concerns had been raised in the past, as a result of routine inspections and two written patient complaints, regarding the infection control procedures in the practice. The deficiencies in infection control practice over a ten year period included a failure to consistently wear gloves while performing EPPs, employ a tray system for sterilising instruments and appropriately store instruments after sterilisation.

The incident management team sought advice from the UK advisory panel for healthcare workers infected with bloodborne viruses (UKAP). The panel noted that as infection control appeared to have been substandard, there was a risk of transmission of BBVs between patients, as well as transmission of HCV from the HCW to patients. Thus, UKAP advised that all the HCW's patients should be contacted and offered testing for HIV, hepatitis B virus (HBV) and HCV.

Records were available on 6,139 patients who had been treated at the practice since 1969. Attempts were made to contact 4,900 of these patients as part of the PNE; it was not possible to trace 587 
patients and 652 were deceased. Testing for BBVs was eventually completed on 2,665 patients. We report the results of a case control study undertaken to investigate the association between treatment by the HCW and infection with a BBV.

\section{METHOD}

An unmatched nested case control study was undertaken to test whether treatment by the HCW was associated with infection with a BBV. Cases were all individuals with laboratory evidence of current or past infection with a BBV, identified as a result of the PNE. Controls were randomly selected individuals tested during the PNE without laboratory evidence of current or past infection with a BBV. Controls were obtained by assigning a random number to the 2,046 individuals who had tested negative by 7 July 2006 using the RAND function in Microsoft Excel. Controls were then selected sequentially from this list starting with the largest random number.

Study power was calculated using DSS Research researcher's toolkit. ${ }^{4}$ The power calculation assumed that the mean number of treatments and standard deviation in controls was the same as the whole cohort and that variance of the mean number of treatments in cases would be equal. Four controls were selected per case. This gave the study a statistical power of 75\% at the 5\% significance level to detect a 50\% greater mean number of attendances for treatment in cases compared to controls.

A standard proforma was designed to record detailed information on the treatment provided by the HCW for the cases and controls. The data was subsequently obtained from each patient record by two authors (SS and BWM).

The proforma captured age, gender and total number of visits (contacts) for each patient. It was also designed to record the date and types of intervention carried out at each visit. Interventions were classified as non-invasive, minimally invasive or invasive. A patient could have more then one intervention in a single visit.

Interventions were classified as noninvasive if limited to advice, instruction or formulation of a treatment plan which did not involve a periodontal
Table 1 Genotyping and sequencing of virus obtained from cases of hepatitis C

\begin{tabular}{l|l|l|l}
\hline Case & Genotype & Sequencing & Alternative risk factors* \\
\hline 1 & 1 & Different from cases 3,5 and 11 & \\
\hline 2 & Not available & Declined testing & Yes \\
\hline 3 & $1 a$ & Different from cases 1,5 and 11 & \\
\hline 4 & Mixed & Sample unsuitable & Yes \\
\hline 5 & $1 a$ & Different from cases 1,3 and 11 & \\
\hline 6 & 2 & No other genotype 2 & \\
\hline 7 & Not available & Not viraemic & Yes \\
\hline 8 & $3 a$ & Different from HCW and case 9 & \\
\hline 9 & $3 a$ & Different from HCW and case 8 & \\
\hline 10 & Not available & Not viraemic & Yes \\
\hline 11 & 1 1a & Different from cases 1,3 and 5 & \\
\hline HCW & $3 a$ & Different from cases 8 and 9 & \\
\hline "The presence of alternative risk factors are only identified when virus was not avalable for sequencing.
\end{tabular}

Table 2 Number of visits for dental treatment and cases of hepatitis C, 19692005

\begin{tabular}{l|l|l|l|l|l}
\hline \multirow{2}{*}{ Treatment } & \multicolumn{2}{|l|}{ Mean number of visits } & \multicolumn{2}{l}{ Mean difference } \\
\cline { 2 - 7 } & $\begin{array}{l}\text { Cases } \\
(\mathrm{n}=11)\end{array}$ & $\begin{array}{l}\text { Controls } \\
(\mathrm{n}=120)\end{array}$ & Difference & $95 \% \mathrm{Cl}$ & $\mathrm{p}$ \\
\hline Attended surgery & 20.2 & 18.6 & 0.9 & $-9.4,12.5$ & 0.78 \\
\hline Clinical examination & 10.5 & 9.7 & 1.1 & $-5.3,7.1$ & 0.78 \\
\hline Any procedure & 15.5 & 13.4 & 2.1 & $-6.1,10.3$ & 0.62 \\
\hline Restorative procedure & 8.9 & 7.5 & 1.5 & $-3.7,6.6$ & 0.58 \\
\hline Periodontal procedure & 4.2 & 3.0 & 1.1 & $-1.4,3.6$ & 0.39 \\
\hline Extraction & 1.3 & 1.0 & 0.2 & $-0.8,1.2$ & 0.65 \\
\hline Minor surgery & 0 & 0.2 & 0.2 & $-0.5,0.1$ & 0.24
\end{tabular}

Table 3 Number of visits for dental treatment and cases of hepatitis B, 19692005

\begin{tabular}{l|l|l|l|l|l}
\hline \multirow{2}{*}{ Treatment } & \multicolumn{4}{|l|}{ Mean number of visits } & \multicolumn{2}{l}{ Mean difference } \\
\cline { 2 - 7 } & $\begin{array}{l}\text { Cases } \\
(\mathrm{n}=20)\end{array}$ & $\begin{array}{l}\text { Controls } \\
(\mathrm{n}=120)\end{array}$ & Difference & $95 \% \mathrm{Cl}$ & $\mathrm{p}$ \\
\hline Attended surgery & 19.9 & 18.6 & 1.2 & $-7.5,9.9$ & 0.78 \\
\hline Clinical examination & 10.8 & 9.7 & 1.1 & $-3.7,6.1$ & 0.65 \\
\hline Any procedure & 14.6 & 13.4 & 1.2 & $-5.4,7.7$ & 0.73 \\
\hline Restorative procedure & 7.0 & 7.5 & -0.5 & $-4.4,3.5$ & 0.82 \\
\hline Periodontal procedure & 4.3 & 3.1 & 1.2 & $-0.9,3.3$ & 0.26 \\
\hline Extraction & 1.7 & 1.0 & 0.7 & $-0.2,1.5$ & 0.14 \\
\hline Minor surgery & 0 & 0.2 & -0.2 & $-0.4,0.05$ & 0.12
\end{tabular}


assessment. Minimally invasive procedures included radiographic examination, stages in the production of dentures and application of preventive measures such as fissure sealants or topical fluoride applications. All other forms of treatment were classified as invasive and included administration of local anaesthesia, restorative procedures involving the removal of tooth tissue (filling, crowns and bridges), endodontic treatment (root fillings), non-surgical periodontal treatment (periodontal assessment, scaling and polishing, root planning and sub-gingival curettage) and extractions and minor oral surgery procedures (surgical removal of roots or unerupted teeth, apicectomy, placement of implants, periodontal surgery, biopsy or other soft tissue surgery). An opportunity was given to record in free text any procedure which did not fall into one of the above categories, but was not required.

Information on lifetime risk factors for BBV infection was obtained during telephone interviews with cases and controls using a structured questionnaire. The information obtained included details of social history (place of birth, ethnicity, periods living outside the UK, periods of incarceration, living in residential accommodation, living with a person with a BBV, hepatitis B status of mother at the time of birth, tattoos, and body piercing) and occupational history (work in healthcare, work in residential accommodation, and work outside the UK). Medical history included details of organ transplants or tissue grafts, renal dialysis, hospital or dental treatment abroad, hepatitis B immunisation, surgical treatment, blood transfusion and the receipt of other blood products. Sexual history involved the recording of number of lifetime partners, gender of sexual partners, condom use and partners who used intravenous drugs. Drug history including details of injecting, snorting or other drug use, injecting in the presence of others, sharing needles, syringes or 'works', and sharing spoons, water, filters, or 'paraphernalia'.

Questionnaire data were collated using Epi Info $6.04^{5}$ and odds ratios, 95\% confidence intervals, chi-square tests, Fisher's exact tests, Mann-Whitney U tests and two-sided t tests were calculated using STATA 10.0. ${ }^{6}$

Primary screening tests were performed on initial serum obtained from patients using multichannel analyser enzyme immunoassays (EIA) for HCV (Abbott AxSym), HBV surface antigen (Abbott AxSym HBSAg), and HIV (Abbott AxSym Combi Kit HIV 1/2). Equivocal HCV EIA screening tests were resolved using recombinant immunoblot assay (RIBA) for HCV antibodies (Chiron RIBA HCV 3.0). A second sample was obtained from patients with positive or unresolved equivocal HCV antibody tests to establish viraemia and genotype using real-time polymerase chain reaction (rt-PCR) to detect $\mathrm{HCV}$ RNA (Roche). To ascertain if samples of the same genotype were linked to the HCW or each other, sequencing studies of a 222-nucleotide fragment of the NS5B sub-genomic region were undertaken to determine phylogeny and homology. Samples that were positive or equivocal for HBV surface antigen were tested for HBV e antigen, e antibody, core IgM and IgG antibody by EIA (Abbott).

\section{RESULTS}

In the 2,665 patients tested for infection, past or present, HCV was confirmed in 11 patients and past HBV infection was demonstrated in 20 patients. The total number of patients with evidence of BBV infection was 30 because one individual had infection with both HBV and HCV. No patients had evidence of current infection with HBV or infection with HIV. The prevalence of HCV infection was $0.41 \%$ (95\% CI $0.21 \%-0.74 \%$ ) and the prevalence of past $\mathrm{HBV}$ infection was $0.75 \%$ (95\% CI 0.46\% - 1.16\%).

Eight of the 11 patients with HCV had current infection demonstrated by HCV RNA viraemia. Four of these were genotype 1 , two genotype 3a, one genotype 2 , and one untypeable (Table 1). The HCW was infected with a genotype 3 a virus.

The response rate for interviews was $83 \%(25 / 30)$ in cases and 56\% (67/120) in controls. All the patient records for cases and controls were available for review. There were no significant differences in the age or gender of cases and controls. The mean age of cases was 57 years and controls 55 years $(p=0.57)$, and the median age of cases was 57 and controls $52(\mathrm{p}=0.37) .47 \%$ of cases $(14 / 30)$ and $36 \%(43 / 120)$ of the controls were male ( $p=0.27)$.

The mean number of visits for treatment was 20.5 in cases and 18.6 in controls; the difference 1.8 (95\% CI -5.4 to 9.1) was not statistically significant ( $p$ $=0.62$ ). The length of time over which patients were treated by the HCW was similar ( $p=0.96)$ in cases (mean 3,328, median 2,192 days) and controls (mean 3,291 , median 2,337 days). No significant differences in the mean number of visits for specific dental treatments were observed in cases of HCV infection (Table 2) and HBV infection (Table 3) compared to controls.

Statistically significant associations were observed between HCV infection and intravenous drug use (OR $\infty$, $\mathrm{p}=0.0001$ ), snorting drugs (OR 40, $\mathrm{p}$ $=0.003)$, a sexual partner who was an intravenous drug user (OR 38, $\mathrm{p}=0.003$ ) and having more than ten lifetime sexual partners (OR 5.1, p = 0.046). Odds ratios of above 3 , which did not reach statistical significance, were observed for a history of working in healthcare, working in a residential home for people with learning difficulties, and hospital treatment outside the UK (Table 4).

Statistically significant associations were observed between HBV infection and intravenous drug use (OR $\infty$, $\mathrm{p}=0.006$ ), living with an individual known to have HBV (OR $\infty, p=0.006$ ), originating from a country with a high prevalence of $\mathrm{HBV}(\mathrm{OR} \infty, \mathrm{p}=0.006)$, working in a residential home for people with learning difficulties (OR 12.5, p = 0.0007), and being born outside the UK (OR 9.3, p = 0.005). Odds ratios of above 8 , which did not reach statistical significance, were observed for men who have sex with men, snorting drugs, and a sexual partner who was an intravenous drug user (Table 5).

\section{DISCUSSION}

The observed prevalence of HCV infection of $0.41 \%$ (95\% CI $0.21 \%-0.74 \%$ ) is similar to the estimated prevalence of $\mathrm{HCV}$ in England of 0.5\%.7 No association between the amount or type of dental treatment and infection with HCV was observed. In the eight cases of HCV who 
agreed to be interviewed, five gave a history of intravenous drug use, three of whom reported sharing needles and the other two reported sharing other paraphernalia used to prepare drugs before injection. A sixth case had not used intravenous drugs but reported snorting heroin. A seventh case had received a blood transfusion in 1987 prior to the introduction of testing blood products for the HCV. The eighth case reported no significant risk factors.

Sequencing of virus isolated from the two patients with genotype 3a infection demonstrated that the viruses were not related to the HCW. Similarly the sequencing of HCV from patients infected with the same genotype showed that the virus was unrelated. The four patients from whom virus was unobtainable all had good alternative explanations for their hepatitis $\mathrm{C}$ virus infection. The history of intravenous drug use in two patients, one of whom had a partner with known hepatitis $C$ infection, a history of blood transfusion prior to the introduction of testing of blood products in the third patient, and a partner with hepatitis $C$ infection, are all more likely sources of infection than transmission from the HCW or another patient. HCV can be transmitted via sexual contact, ${ }^{8}$ albeit less efficiently than other BBVs. Although the risk of sexual HCV acquisition is low, sex is such a common behaviour that it is thought to account for around a fifth of acute HCV infections in the USA. ${ }^{8}$ Alternatively, other routes of intrafamilial transmission ${ }^{9}$ or undisclosed common risk factors may explain infection in partners of known cases of HCV infection. ${ }^{10}$

There was no evidence which demonstrated transmission of HCV from the HCW to a patient or from patient-topatient via inadequate decontamination or contamination of surgical instruments. The evidence available from patients who presented for testing suggests that this was extremely unlikely to have occurred. To absolutely exclude transmission, all patients would need to be tested. However, the negative findings in the $43 \%(2,665 / 6,138)$ of patients who were alive, traced and tested suggests that the occurrence of transmission was zero or very low.

Table 4 Univariate analysis of risk factors and cases of hepatitis C from patient interview

\begin{tabular}{|c|c|c|c|c|c|c|c|}
\hline \multirow{3}{*}{ Risk factor } & \multirow{2}{*}{\multicolumn{2}{|c|}{$\begin{array}{l}\text { Cases } \\
(n=8) \\
\text { Exposed }\end{array}$}} & \multirow{2}{*}{\multicolumn{2}{|c|}{$\begin{array}{l}\text { Controls } \\
(n=67)\end{array}$}} & \multirow{3}{*}{$\begin{array}{l}\text { Odds } \\
\text { ratio }\end{array}$} & \multirow{3}{*}{$95 \% \mathrm{Cl}$} & \multirow{3}{*}{$\mathrm{p}$} \\
\hline & & & & & & & \\
\hline & Yes & No & Yes & No & & & \\
\hline Born outside UK & 0 & 8 & 2 & 65 & 0 & $0-18$ & 1.0 \\
\hline Lived outside UK & 3 & 5 & 16 & 51 & 1.9 & $0.3-11$ & 0.41 \\
\hline Lived with a case of hepatitis C & 1 & 7 & 0 & 67 & $\infty$ & $0-\infty$ & 0.11 \\
\hline Lived in residential accommodation & 0 & 8 & 1 & 66 & 0 & $0-\infty$ & 1.0 \\
\hline Inmate in prison or a detention centre & 1 & 7 & 0 & 67 & $\infty$ & $0-\infty$ & 0.11 \\
\hline Worked in healthcare & 3 & 5 & 11 & 56 & 3.1 & $0.4-18$ & 0.16 \\
\hline Worked in a residential home & 1 & 7 & 2 & 65 & 4.6 & $0.1-97$ & 0.29 \\
\hline Worked outside the UK & 2 & 6 & 11 & 56 & 1.7 & $0.1-11$ & 0.62 \\
\hline Injected drugs & 5 & 3 & 0 & 67 & $\infty$ & $22-\infty$ & 0.0001 \\
\hline Snorted drugs & 3 & 5 & 1 & 66 & 40 & $2.4-2,107$ & 0.003 \\
\hline Sexual partner IV drug user & 3 & 5 & 1 & 66 & 38 & $2.3-2,044$ & 0.003 \\
\hline Over 5 sexual partners & 5 & 3 & 18 & 49 & 4.5 & $0.8-31$ & 0.053 \\
\hline Over 10 sexual partners & 4 & 4 & 11 & 56 & 5.1 & $0.8-31$ & 0.046 \\
\hline Over 20 sexual partners & 2 & 6 & 4 & 63 & 5.3 & $0.4-45$ & 0.12 \\
\hline Never use condom & 2 & 6 & 19 & 48 & 0.8 & $0.1-5.3$ & 1.0 \\
\hline Tattoo & 0 & 8 & 6 & 61 & 0 & $0-5.4$ & 1.0 \\
\hline Ears pierced & 6 & 2 & 41 & 26 & 1.9 & $0.3-20$ & 0.70 \\
\hline Other body piercing & 0 & 8 & 1 & 66 & 0 & $0-\infty$ & 1.0 \\
\hline Blood product before 1991 & 1 & 7 & 11 & 56 & 0.7 & $0-6.7$ & 1.0 \\
\hline Surgery & 7 & 1 & 56 & 11 & 1.4 & $0.1-68$ & 1.0 \\
\hline Hospital treatment outside UK & 2 & 6 & 5 & 62 & 4.1 & $0.3-32$ & 0.16 \\
\hline Dental treatment outside UK & 0 & 8 & 4 & 63 & 0 & $0-8.6$ & 1.0 \\
\hline
\end{tabular}

No patients tested positive for HIV infection and thus patient-to-patient transmission of HIV did not occur in the patients who were tested. All the patients with HBV infection had resolved or past infection. The absence of circulating virus means that it is not possible to investigate the possibility of patientto-patient transmission with genetic sequencing. Epidemiology is the only method available for this investigation.

Data with which to compare the observed prevalence of past HBV infection of $0.76 \%$ (95\% CI $0.46 \%-1.17 \%$ ) is limited. A 1998 population-based study in the Republic of Ireland found anti-HBc in $0.29 \%(5 / 1,714)$ of specimens tested. ${ }^{11}$ A 1996 study of residual diagnostic sera in England and Wales found anti-HBc in $2.5 \%(75 / 3,039)$ of specimens tested from outside of London. ${ }^{12}$ However, the prevalence in these selected samples in different areas was highly dependent on the proportion of the population born in Africa and Asia. In the LHB served by the practice, only $1.6 \%$ of the population was born outside of the European Union and as a result, the predicted prevalence from these data would be much lower than 2.5\%. A study of blood donors in the South West of England in 1979 reported a prevalence of anti$\mathrm{HBc}$ of $0.7 \%$ in new donors and $0.4 \%$ in established donors. ${ }^{13}$ The prevalence in West Yorkshire firemen in 1988 was reported as $0.6 \%(1 / 173)^{14}$ and in Lancashire police officers $2.8 \%(8 / 284) .{ }^{15}$ The observed prevalence, $0.76 \%$, of anti-HBc 
in this investigation is at a level that might reasonably be expected.

No association between the amount or type of dental treatment and infection with HBV was observed. Among the 18 cases of HBV that were interviewed, two cases gave a history of intravenous drug use, two cases had an ethic origin and were born in countries with a high prevalence of $\mathrm{HBV}$, one case was a man who had sex with men, one case, who did not have a history of intravenous drug use, had a sexual partner who did and was known to have a history of hepatitis B, two cases, without other risk factors, had worked in a residential home for people with learning disabilities, and a ninth case had a history of jaundice six months after receiving a blood transfusion prior to the introduction of testing blood products for the hepatitis $B$ virus. Risk factors were not identified to explain the remaining nine cases, although an elevated but not statistically significant odds ratio of 2.5 for more than ten sexual partners suggests that a proportion of these cases are likely to be due to heterosexual transmission. These findings are similar to other UK studies in which the probable means of acquisition was known for just over half of all adult cases of acute HBV infection. ${ }^{16}$

There is no evidence which demonstrates patient-to-patient transmission of HBV. The available evidence from the data on prevalence and the case control study suggests that the occurrence of patient-to-patient transmission of the HBV arising from deficiency in infection control practice was zero or low.

The initial risk assessment conducted by the NPHS concluded that the risk of patient-to-patient transmission of a BBV infection was probably very small but not zero. The assessment was reliant on there being a low prevalence of BBV infections in the relevant community rather than on the safety of the infection control procedures in operation. Testing demonstrated that the assumption underpinning this risk assessment was correct.

Transmissions of BBVs from HCWs to patients are well documented. The limited occasions when HIV transmission has been demonstrated include a dentist to a patient. ${ }^{17}$ Prior to routine

Table 5 Univariate analysis of risk factors and cases of hepatitis B from patient interview

\begin{tabular}{|c|c|c|c|c|c|c|c|}
\hline \multirow{3}{*}{ Risk factor } & \multirow{2}{*}{\multicolumn{2}{|c|}{$\begin{array}{l}\text { Cases } \\
(n=18) \\
\text { Exposed }\end{array}$}} & \multirow{2}{*}{\multicolumn{2}{|c|}{$\begin{array}{l}\text { Controls } \\
(n=67) \\
\text { Exposed }\end{array}$}} & \multirow{3}{*}{$\begin{array}{l}\text { Odds } \\
\text { ratio }\end{array}$} & \multirow{3}{*}{$95 \% \mathrm{Cl}$} & \multirow{3}{*}{$\mathrm{p}$} \\
\hline & & & & & & & \\
\hline & Yes & No & Yes & No & & & \\
\hline Born outside UK & 4 & 14 & 2 & 65 & 9.3 & $1.2-108$ & 0.005 \\
\hline Ethnic origin high prevalence & 2 & 16 & 0 & 67 & $\infty$ & $2.0-\infty$ & 0.006 \\
\hline Lived outside UK & 8 & 10 & 16 & 51 & 2.6 & $0.7-8.6$ & 0.09 \\
\hline Lived with a case of hepatitis B & 2 & 16 & 0 & 67 & $\infty$ & $2.0-\infty$ & 0.006 \\
\hline Lived in residential accommodation & 0 & 18 & 1 & 66 & 0 & UD & 0.60 \\
\hline Worked in healthcare & 2 & 16 & 11 & 56 & 0.6 & $0.1-3.4$ & 0.58 \\
\hline Worked in a residential home & 5 & 13 & 2 & 65 & 12.5 & $1.7-138$ & 0.0007 \\
\hline Worked outside the UK & 6 & 12 & 11 & 56 & 2.5 & $0.6-9.3$ & 0.11 \\
\hline Injected drugs & 2 & 16 & 0 & 67 & $\infty$ & $2.0-\infty$ & 0.006 \\
\hline Snorted drugs & 2 & 16 & 1 & 66 & 8.3 & $0.4-494$ & 0.11 \\
\hline Sexual partner IV drug user & 2 & 16 & 1 & 66 & 8.3 & $0.4-494$ & 0.11 \\
\hline Over 5 sexual partners & 7 & 11 & 18 & 49 & 1.7 & $0.5-5.8$ & 0.32 \\
\hline Over 10 sexual partners & 6 & 12 & 11 & 56 & 2.5 & $0.6-9.3$ & 0.18 \\
\hline Over 20 sexual partners & 2 & 16 & 4 & 63 & 2.0 & $0.2-15$ & 0.45 \\
\hline Never use condom & 8 & 10 & 19 & 48 & 2.0 & $0.6-6.7$ & 0.19 \\
\hline Men who have sex with men & 1 & 17 & 0 & 67 & $\infty$ & $0-\infty$ & 0.05 \\
\hline Tattoo & 2 & 16 & 6 & 61 & 1.3 & $0.1-8.0$ & 0.78 \\
\hline Ears pierced & 8 & 10 & 41 & 26 & 0.5 & $0.2-1.7$ & 0.20 \\
\hline Other body piercing & 0 & 18 & 1 & 66 & 0 & UD & 0.60 \\
\hline Blood product before 1970 & 1 & 17 & 2 & 65 & 1.9 & $0.03-38$ & 0.52 \\
\hline Surgery & 14 & 4 & 56 & 11 & 0.7 & $0.2-3.4$ & 0.57 \\
\hline Hospital treatment outside UK & 3 & 15 & 5 & 62 & 2.5 & $0.3-14$ & 0.24 \\
\hline Dental treatment outside UK & 2 & 16 & 4 & 63 & 2.0 & $0.2-15$ & 0.45 \\
\hline
\end{tabular}

immunisation, transmission of $\mathrm{HBV}$ between dentist and patient occurred more frequently, but was last described in $1986 .{ }^{18}$ Transmission of HCV from a dentist to a patient has never been demonstrated. ${ }^{19}$ In the absence of prior evidence of transmission, the PNE would not have been undertaken if recommended infection control practice, in particular the consistent use of gloves while performing EPPs, had been implemented by the HCW. Completion of this investigation, which detected no transmission from the HCW to patients, reinforced the judgement that PNEs are not normally indicated and provides evidence to suggest that PNEs may not be necessary for lower risk EPPs even when the HCW has not consistently worn gloves.

Notification of patients identified as having been exposed to a risk of BBV infection from other patients is undertaken to provide patients with information about the nature of the risk to which they have been exposed, detect any BBV infection, provide care to the infected person and advice on measures to prevent onward BBV transmission, and obtain valid data to augment existing estimates of the risk of BBV transmission from patient-to-patient. Although individual and population health gain may have arisen from the detection of incidental cases of $\mathrm{HCV}$ in this PNE, 
population screening is not currently recommended. The PNE provides empirical evidence to support the conclusions of Millership et al., ${ }^{3}$ who estimated that less than one case of BBV transmission would occur following a failure of decontamination of dental instruments and thus took no action following three separate incidents of decontamination failure. A PNE following a dentist's admission of the periodic use of unsterilised equipment did not detect transmission of BBV. ${ }^{20}$ Although the risks are low they are not zero, as patient-to-patient transmission of HBV has been described on one occasion in a dental practice. ${ }^{21}$

The very significant costs of PNEs probably outweigh the limited benefits. Patients who are contacted during PNEs report feeling anxious on receiving the letter, but almost all believe patients should always be informed following treatment by an infectious HCW, even when the risks are very small. ${ }^{22}$ The consequences of infection with a BBV for a HCW are grave and any unnecessary addition to this unfortunate personal experience should be avoided..$^{19,23,24}$

Patient-to-patient transmission of BBVs was not demonstrated in the PNE despite comprehensive virological and epidemiological investigation. In incidents where transmission has not been identified, the risk of patient-to-patient transmission is very low. Practice with respect to PNEs following infection control failures varies within the NHS. We suggest that the National Institute for Health and Clinical Excellence should be asked to produce guidance for the NHS which will combine a robust economic evaluation with the views of stakeholders including patients.

We would like to thank: staff at the NPHS laboratories in Cardiff and Bangor, and the Centre for Infection London, who processed samples; staff from Gwynedd Local Health Board who administered the PNE and located records for the case control study; and members of the North Wales Health Protection Team who interviewed patients.

1. Department of Health. Hepatitis C infected health care workers. London: DoH, 2002, publication no. HSC 2002/010.

2. Advisory Group on Hepatitis. Minutes of meeting held on Wednesday 26 October 2005 at Department of Health, Skipton House, London SE1 starting at 10:30am. London: DoH, 2005, publication no. AGH 2006/01. www.advisorybodies.doh.gov. uk/agh/minutesmeeting26oct05.pdf

3. Millership S E, Cummins A J, Irwin D J. Infection control failures in a dental surgery - dilemmas in incident management. J Public Health 2007; 29: 303-307.

4. DSS Research. Researcher's toolkit wesbite, two sample tests using average values. http://www. dssresearch.com/toolkit/spcalc/power_a2.asp (accessed 25 June 2008)

5. Epidemiology Program Office. Epi Info version 6.04d. Atlanta: Centers for Disease Control and Prevention, 2001.

6. StataCorp. Stata Statistical Software: release 10.0 Texas: Stata Corporation, 2007.

7. Health Protection Agency. Hepatitis C in England. The first Health Protection Agency annual report 2005. London: HPA, 2005.

8. Terrault N A. Sexual activity as a risk factor for hepatitis C. Hepatology 2002; 36(Suppl 1): s99-s105.

9. Orlando $R$, Lirussi F. Hepatitis $C$ virus infection: sexual or non-sexual transmission between spouses? A case report and review of the literature. Infection 2007; 35: 465-468.

10. Minola E, Baldo V, Baldovin T, Trivello R, Florean A. Intrafamilial transmission of hepatitis $C$ virus infection. Eur J Epidemio/ 2006; 21: 293-297.

11. O'Connell T, Thornton L, O'Flanagan D et al. Prevalence of heapatitis B anti-core antibody in the Republic of Ireland. Epidemiol Infect 2000; 125: 701-704

12. Gay N J, Hesketh L M, Osborne K P, Farrington C $P$, Morgan-Capner P, Miller E. The prevalence of hepatitis B infection in adults in England and Wales. Epidemiol Infect 1999; 122: 133-138.

13. Archer A C, Cohen B J, Mortimer P P. The value of screening blood donors for antibody to hepatitis $B$ core antigen. J Clin Pathol 1983; 36: 924-928.

14. Crosse B A, Teale C, Lees E M. Hepatitis B markers in West Yorkshire firemen. Epidemiol Infect 1989; 103: 383-385.

15. Morgan-Capner $P$, Hudson P, Armstrong A. Hepatitis B markers in Lancashire police officers. Epidemiol Infect 1988; 100: 145-151.

16. Balogun M A, Ramsay M E, Fairley C K, Collins M, Heptonstall J. Acute hepatitis B infection in England and Wales: 1985-96. Epidemiol Infect 1999; 122: 125-131.

17. Ou CY, Ciesielski C A, Myers G et al. Molecular epidemiology of HIV transmission in a dental practice. Science 1992; 256: 1165-1171.

18. Centers for Disease Control. Outbreak of hepatitis B associated with an oral surgeon - New Hampshire. MMWR Morb Mortal Wkly Rep 1987; 36: 132-133.

19. Croser D. Written off. Br Dent J 2006; 201: 497-499

20. Roy K M, Ahmed S, Cameron S O, Shaw L, Yirrell D, Goldberg D. Patient notification exercise following a dentist's admission of the periodic use of unsterilized equipment. J Hosp Infect 2005; 60: 163-168.

21. Redd J T, Baumbach J, Kohn W, Nainan O, Khristova M, Williams I. Patient-to-patient transmission of hepatitis B virus associated with oral surgery. $J$ Infect Dis 2007: 195: 1311-1314.

22. Blatchford O, O'Brien S, Blatchford M, Taylor A. Infectious health care workers: should patients be told? J Med Ethics 2000; 26: 27-33.

23. Hancocks S. Losing your livelihood just twenty minutes from now. Br Dent J 2006; 201: 485.

24. Hancocks S. Blood-borne one year on. Br Dent J 2007; 203: 439 . 